Archive for

Organic Chemistry

Arkivoc 2020, part iii, 24-39

\title{
Continuous flow synthesis of pharmaceuticals in Africa
}

\author{
Cloudius R. Sagandira, McQuillan Moyo and Paul Watts* \\ Nelson Mandela University, University Way, Port Elizabeth, 6031, South Africa \\ Email: Paul.Watts@mandela.ac.za
}

Received 04-07-2020

Accepted 06-15-2020

Published on line 06-27-2020

\section{Abstract}

Africa has a huge disease burden due to its poverty, geography, poor health care and practices, thus drawing the continent from its aspiration of guaranteeing its citizens high standard of living, quality of life and wellbeing as envisaged by Africa's agenda 2063. It over relies on the European and Asian pharmaceutical market for the import of APIs used in the manufacture of most of the drugs of importance. This often affects accessibility of medicines due to unreliable supply chains and high costs, which exerts a huge financial burden on many states. This can be alleviated by investing in local drug manufacturing. Since the pharmaceutical manufacturing industry in not well developed, Africa can take advantage of the latest technologies such as continuous flow chemistry to establish future proof and state-of-the-art manufacturing infrastructure. This review highlights some of the work done in continuous flow API synthesis in Africa to show its potential application in the local pharmaceutical industry.
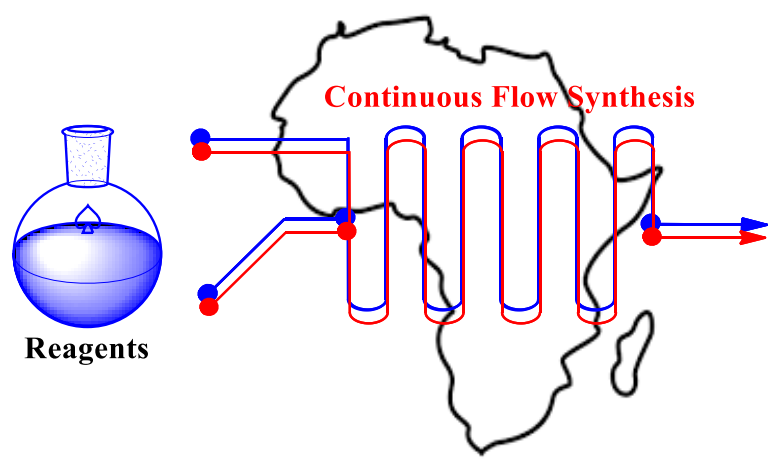

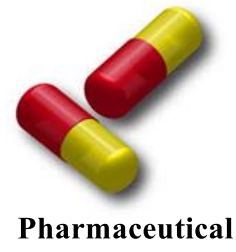

Drugs

Keywords: Africa, API, continuous flow chemistry, local manufacturing. 


\section{Table of Contents}

1. Introduction

2. Continuous Flow Synthesis of APIs

2.1. Continuous flow synthesis of APIs in Africa

2.1.1. Lamivudine and Emtricitabine

2.1.2. Efavirenz

2.1.3. Oseltamivir phosphate

2.1.4. Isoniazid

2.1.5. Clozapine

3. Conclusions

\section{Introduction}

Africa has high prevalence of communicable diseases, chief among them are the HIV/AIDS pandemic, malaria and tuberculosis, resulting in a high demand for important medicines. ${ }^{1,2}$ An estimated $70-90 \%$ of the active pharmaceutical ingredients (APIs) used in the manufacture of these drugs are imported from India, China and Europe. ${ }^{3}$ Africa cannot meet the demand for these drugs as there are a few companies in Africa involved in the manufacture and formulation of APIs thus the high demand on imports. ${ }^{4}$ Africa continues to spend enormous sums of money to import APIs annually with South Africa having the fifth highest spending per capita on pharmaceuticals in the world. ${ }^{5}$ The fluctuating exchange rate and scarce foreign currency required for importing APIs puts a strain on the economy and subsequently on the households who are the consumers of the final product.

When it comes to the fight against bacteria it is widely and unfavourably known that antimicrobial resistance $(A M R)$ is a global phenomenon with dire consequences, though more prevalent in Africa. ${ }^{6}$ It has been reported that the current global mortality rate due to AMRs stands at 700000 annually and if no action is taken the figure is estimated to rise to above 10 million by $2050 .^{7,8}$ It is projected that this could translate to a cost of 100 trillion US dollars on the global economy. ${ }^{8}$ In order to avoid losing the battle against microbes it is imperative that we ensure compliance in antibiotic therapy. It should however be noted that part of the problem in compliance is a result of a shortage in drugs, especially among the poor communities in Africa. Coupled to this shortage is the high cost of medication, which is generally unaffordable to the poor communities in Africa. It is therefore important to ensure that Africa can be self-sufficient in producing medicines as this will lead to improved health outcomes and direct or indirect benefits on the economy. ${ }^{4}$ Even though Sub-Saharan Africa is the epicenter of the HIV and AIDS pandemic and has a high demand for antiretroviral drugs it lags in the API manufacturing race with only 9 of the 46 countries active, serving a population of 1.06 billion. ${ }^{9}$ In comparison to countries with similar population there are 10500 and $5000 \mathrm{drug}$ manufacturing companies in India and China respectively, our biggest rival and suppliers in API manufacturing. ${ }^{10}$

Encouragingly, some governments have considered promoting local production of pharmaceuticals to mitigate the aforementioned problems. In this vain it is important to make serious considerations on the technologies to implement when investing in API manufacturing. There are many huddles that would have to be overcome but the honor lies with governments to offer an attractive environment for business; both local startup and established companies wishing to expand their operations into the continent. For example, the 
licensing system by governments has ensured that they have access to the patents for the anti-retroviral therapy (ART) drugs as agreed upon in Doha Declaration, which has helped reduce the price of these drugs. ${ }^{9}$ This is particularly advantageous as it cuts down the huge costs involved in drug discovery. The generics that are manufactured are strictly monitored to ensure that they conform to the United States, Food and Drug Administration (FDA) standards for purity, quality and activity. ${ }^{11}$

There are many advantages of setting up local API manufacturing, including improved public health care as a result of improved accessibility and awareness of the required drugs. This has been one of the driving forces for local API manufacturing for HIV drugs for instance since Sub-Saharan Africa is the focal point of the HIV/AIDS pandemic with a high demand for ARV drugs. The major challenge that however remains to be ascertained is the viability of producing APIs locally when compared to the generics from overseas suppliers such as those from China and India. The cost of ART has gone down significantly from the early 2000s to date, from US\$ 10,439 per patient per year is now less than US\$ 100 for the same. ${ }^{10,12}$ This has been a result of governments coming together to loosen trade restrictions and promote external players in supplying more affordable generics according to the Trade Related Aspects of Intellectual Property (TRIPS). ${ }^{9}$

In Africa, the leading company to pioneer the formulation of pharmaceuticals in particular ARVs, was Aspen Pharmacare that began with the drug Stavudine in 2003. ${ }^{10,13}$ Presently, there are a few pharmaceutical companies that manufacture (i.e. formulate APIs into a dose that the patient can take) ART triple combination drugs, of which Aspen is one of them, however their competitiveness in terms of price, in relation to the export options is yet to be established. In South Africa, the supply of ARVs is based on a tender system, in which manufacturers bid to government tenders that are offered every three years. The manufacturers that got the biggest portions in the past year were Mylan, an international company that manufactures in India. They also supply most of the local companies that produce generics with APIs.

There are several factors that affect local production of ARVs, which include availability of infrastructure, skilled labour and financial support, which often involves government support. ${ }^{10,14,15}$ It should be noted that most of the ARV drugs that are distributed in most of the countries in Sub-Saharan Africa are sponsored by donors. ${ }^{10,12,14}$ One of the major concerns with donors supporting local production versus imported generics is the difference in cost between the two and the ability to meet the WHO and FDA standards by local manufacturers. ${ }^{10}$ The global economic crisis that began in 2008 seriously affected the flow of donor funds for ART programmes. The past few years have been characterised by the continual reduction in donor funds to low-income and middle-income countries in sub-Saharan Africa, from international aid organisation such as the United States President's Emergency Plan for AIDS Relief (PEPFAR). ${ }^{14}$

Africa can take advantage of the fact that most countries have a chemical industry that is under capacitated or even non-existent in some cases to adopt emerging enabling technologies such as continuous flow manufacturing to establish state-of-the-art infrastructure for local manufacturing. In contrary, such technologies are deemed disruptive in developed economies with well-established traditional batch manufacturing infrastructure. We envisage that not all drugs can be manufactured locally at competitive price to the Asian imports. It is therefore critical to make the right choice of drugs to manufacture, as it would be beneficial to start with low volume high value drugs, that would be quicker to offset the initial investment. It is important to take the following into considerations prior to establishing a continuous manufacturing plant; the availability of raw materials and intermediate supplies, the ability to telescope the synthetic route and also the possibility to be able to develop multi-purpose facilities. ${ }^{16}$

Flow chemistry technology, in which reactions occur in a continuous flow stream, offers a lucrative option as a future proof technology that can set Africa as a global competitor in API manufacturing. In recent years continuous flow technology has received considerable attention due to its numerous well documented 
advantages over the conventional batch process such as efficiency, easy scale-up, enhanced safety and reproducibility. ${ }^{17-21}$ Some success stories that have resulted in industrial production include the synthesis of Lombustine a drug used to treat brain tumors $\left(1.6 \mathrm{~L} / \mathrm{min}\right.$, Total $200 \mathrm{Kg}$ per day), ${ }^{22}$ Prexasertib monolactate monohydrate a cancer drug $\left(3 \mathrm{~kg} /\right.$ day, Total of $24 \mathrm{~kg}$ ), ${ }^{23}$ Merestinib a cancer drug (Total $250 \mathrm{Kg} / \mathrm{day}$ in a $12-\mathrm{L}$ reactor inside a steam shell at $150^{\circ} \mathrm{C}, 100$-min mean residence time). ${ }^{24}$ Herein, we explore some of the African success stories in the synthesis of APIs and intermediates using continuous flow technology.

\section{Continuous Flow Synthesis of APIs}

In recent years, the adoption of continuous flow technology in API and pharmaceutical drugs synthesis research has significantly increased. Numerous continuous flow procedures towards various drugs have been developed demonstrating several advantages over the batch procedures. ${ }^{5,16,25-27}$ Although this review is exclusively focusing on flow drug procedures developed in Africa, a few selected examples of continuous flow drugs procedures developed outside Africa are highlighted in Table 1.

Table 1. Selected drugs made outside Africa using continuous flow technology

\begin{tabular}{ll}
\hline Authors & Kobayashi et al. ${ }^{28}$
\end{tabular}


Table 1. Continued

Kulkarni et al. ${ }^{30}$

\subsection{Continuous flow synthesis of APIs in Africa}

As aforementioned, numerous synthetic routes for APIs and pharmaceutical drugs are being redesigned around continuous flow technology in academia and industry due to its associated advantages over the conventional batch process. Researchers in Africa have embarked on the development of continuous flow routes for various APIs as capacity development towards the grand vision of establishing local drug manufacturing in flow to improve medicine availability in the continent. With this in mind, the on-going API continuous flow synthesis research in Africa are reviewed herein.

2.1.1. Lamivudine and Emtricitabine. Lamivudine (3TC) and emtricitabine (FTC) are both antiviral agents for HIV/AIDS. Mandala et al. developed an improved, greener and safer synthetic route for the preparation lamivudine ( $25 \%$ overall yield) and emtricitabine ( $21 \%$ overall yield) in batch before transferring it to flow. ${ }^{32}$ The initial step involved treating L-menthol $\mathbf{1}$ with glyoxylic acid $\mathbf{2}$ in cyclohexane to yield L-menthyl glyoxylate monohydrate (LMGH) 3 (87\%). One of the key intermediates, 5-hydroxy oxathiolane $\mathbf{5}$ was synthesized in a solvent and catalyst free reaction with reduced reaction time (3.5 hours quicker) (Scheme 1). This is advantageous in that it has a potential to significantly lower the cost of production and ease the process by eliminating complex isolation procedures. Intermediate $\mathbf{5}$, was alternatively synthesised in the presence of solvent with the highest yields obtained with $n$-butanol or MTBE whereas most reports use toluene. In both cases solvent free and with solvent the crude mixture was treated with TEA in heptane according to literature to afford $5^{32}$ The next step was the acetylation of 5 , in the presence of acetic anhydride (2.0 eq.) and sodium bicarbonate (2.0 eq.) compared previous reports where they used the smelly and toxic base, pyridine (6.0 eq.) 
in dichloromethane. ${ }^{32,33}$ The mixture of diastereomers thus obtained was then treated with $n$-Hexane and TEA to obtain the desired intermediate 7 .

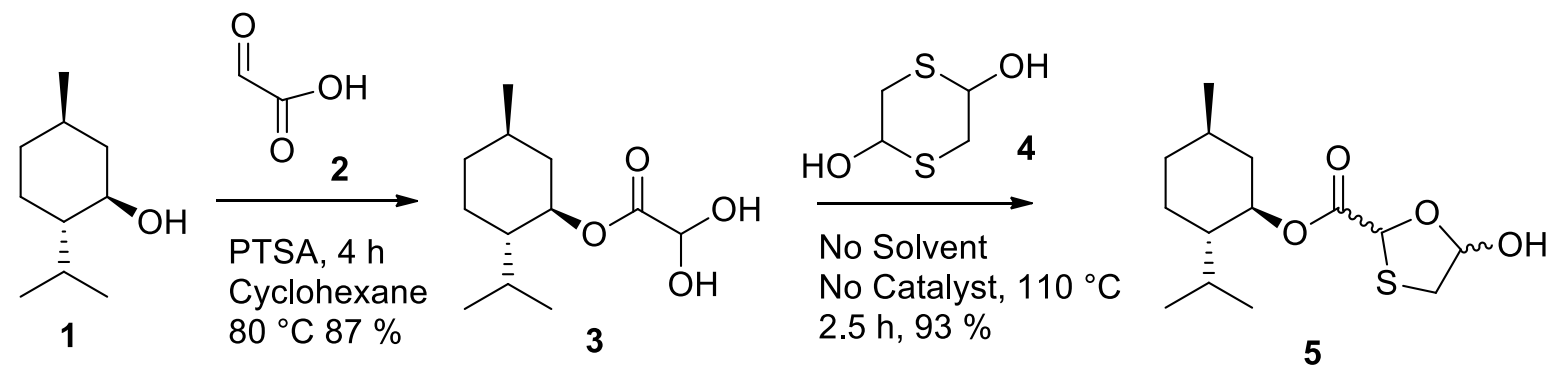

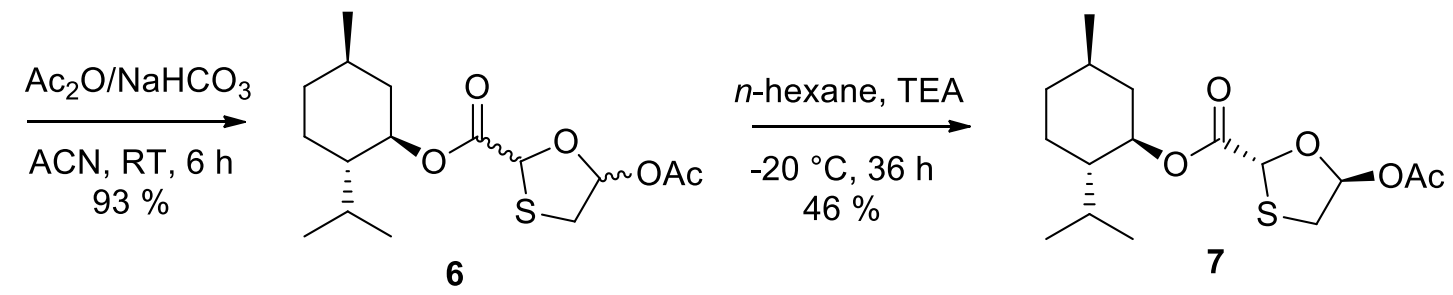<smiles>[R]C1CNC(=O)N=C(N)C1CO[Ge]</smiles><smiles>[R]c1cn([C@H]2CS[C@@H](CO)O2)c(=O)nc1N</smiles><smiles>[R]c1cn(C2CO[C@@H](C(=O)O[C@H]3C[C@H](C)CC[C@H]3C(C)C)S2)c(=O)nc1N</smiles>

8a; $\mathrm{R}=\mathrm{H}$ : cytosine $8 b ; R=F$ : fluro cytosine

9a: $\mathrm{R}=\mathrm{H}$ 9b: $R=F$

11a: 3TC R=H; $88 \%$ 11b: FTC R=F; $79 \%$

10a: R=H; $82 \%$

10b: R=F; $76 \%$

Scheme 1. Synthesis of lamivudine 11a and emtricitabine $\mathbf{1 1 b .}$

Another important step in optimising the synthesis of 3TC and FTC is the $N$-glycosidation reaction to overcome the stereoselectivity barrier, to obtain the required isomer (Cis (-)) and improve the economics for the reaction. Pyridinium triflate with acetonitrile as a solvent was found to be the most ideal catalyst for the reaction when compared to other Lewis acid catalysts such as $\mathrm{ZrCl}_{4}$ and $\mathrm{SnCl}_{4}$, yielding 10a (82\% yield). This use of pyridinium triflate as an $\mathrm{N}$-glyoxylate agent was novel and advantageous when compared to the Lewis acids that are commonly used for the same as they tend to be toxic, highly reactive and unstable and is also 
more expensive. The final step involved reduction with $\mathrm{K}_{2} \mathrm{PO}_{4}$ and $\mathrm{NaBH}_{4}$ in a 1:1 mixture of water and methanol giving 11 a ( $88 \%$ yield) and $11 b$ (79\% yield). ${ }^{32}$

The authors subsequently investigated process transfer into flow after successful batch procedure development. They started by demonstrating the continuous flow synthesis of the starting material, L-menthyl glyoxylate monohydrate (LMGH) 3. LMGH 3 was synthesized from L-menthol 1 and glyoxylic acid 2 (6 eq.) in modest to good yields, $19-78 \%$ and $32-92 \%$ selectivity with the microwave assisted flow reactor giving the best results at $120^{\circ} \mathrm{C}$ and a residence time of 2.8 mins.

Mandala et al. successfully transferred the batch process (Scheme 1) into a continuous flow system (Figure 1). Intermediate 6 was obtained after telescoping the condensation and acetylation reactions with a conversion of $95 \%$, therefore eliminating work up stage between the two steps. The initial step involved treating L-menthyl glyoxylate 3 with 1,4-dithiane-2,5-diol 4 in a $2 \mathrm{ml}$ glass reactor at $90^{\circ} \mathrm{C}$ under 10 psi back pressure using acetonitrile as a solvent. The subsequent stream was treated with acetic anhydride/pyridine in acetonitrile at room temperature in a $1.9 \mathrm{ml}(0.2 \mathrm{ml}$ static mixer $+1.7 \mathrm{ml}$ LTF reactor volume) reactor to give acetylated 1,3-oxathiolane (95\% conversion) in 9.7 min residence time. The isomer of choice 7 was obtained after offline recrystallisation with $1 \%$ triethylamine/hexane, with $45 \%$ yield.

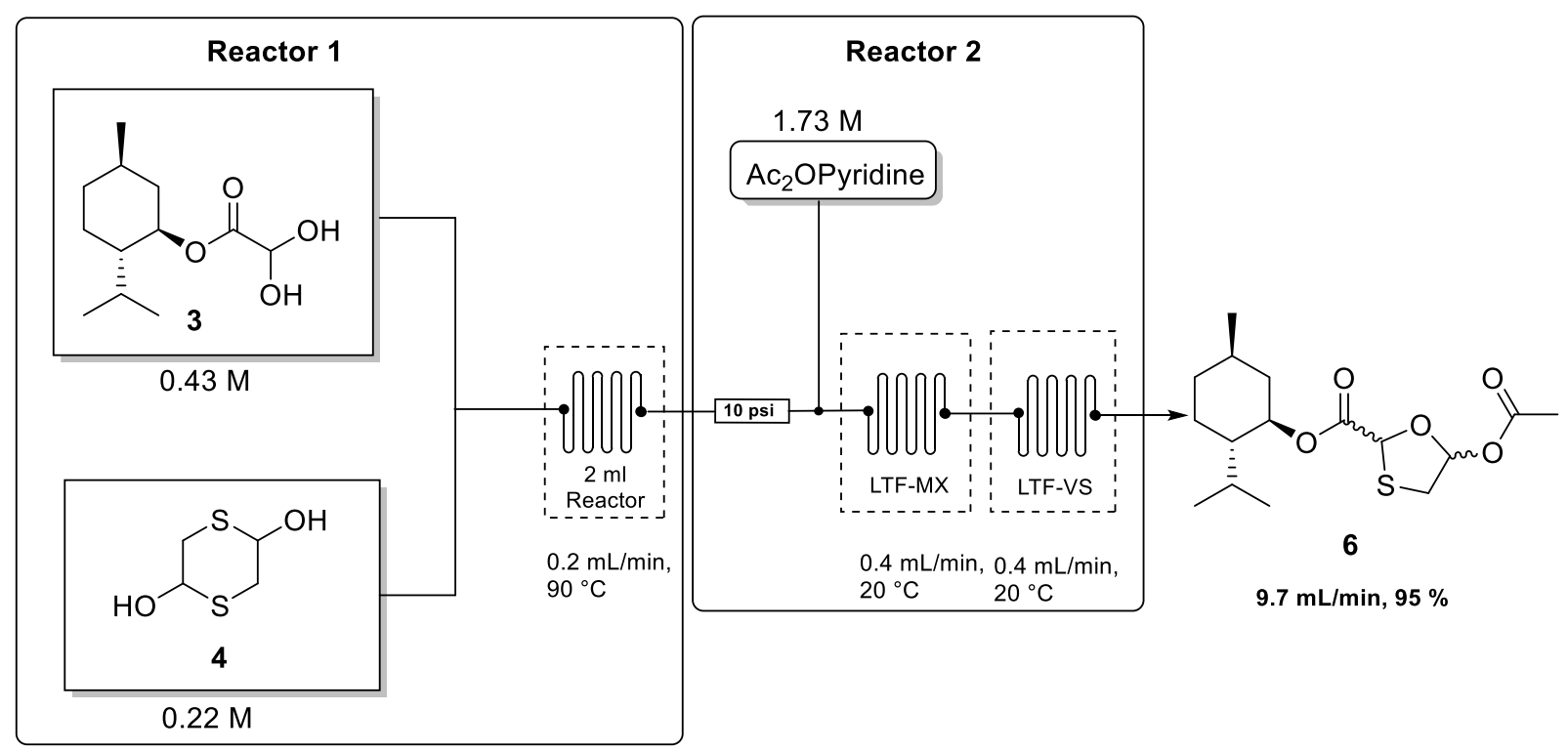

Figure 1. Flow schematic of the synthesis of 5-acetoxy oxathiolane 6 intermediate.

In the penultimate step, 5-acetoxy oxathiolane 7 was treated with pyridinium triflate an $\mathrm{N}$-glycosylating agent to afford compound 10a (95\%) (Scheme 2). The pre-silylated nucleobase (via batch); cytosine 9a in acetonitrile was subsequently introduced into the stream by means of a T-mixer and allowed to react in a PTFA coil reactor tubing $(3.4 \mathrm{~mL})$. The resultant mixture was heated at $80^{\circ} \mathrm{C}$ over a residence time of $8.4 \mathrm{mins}$ to afford $10 \mathrm{a}$ in $95 \%$ yield. 

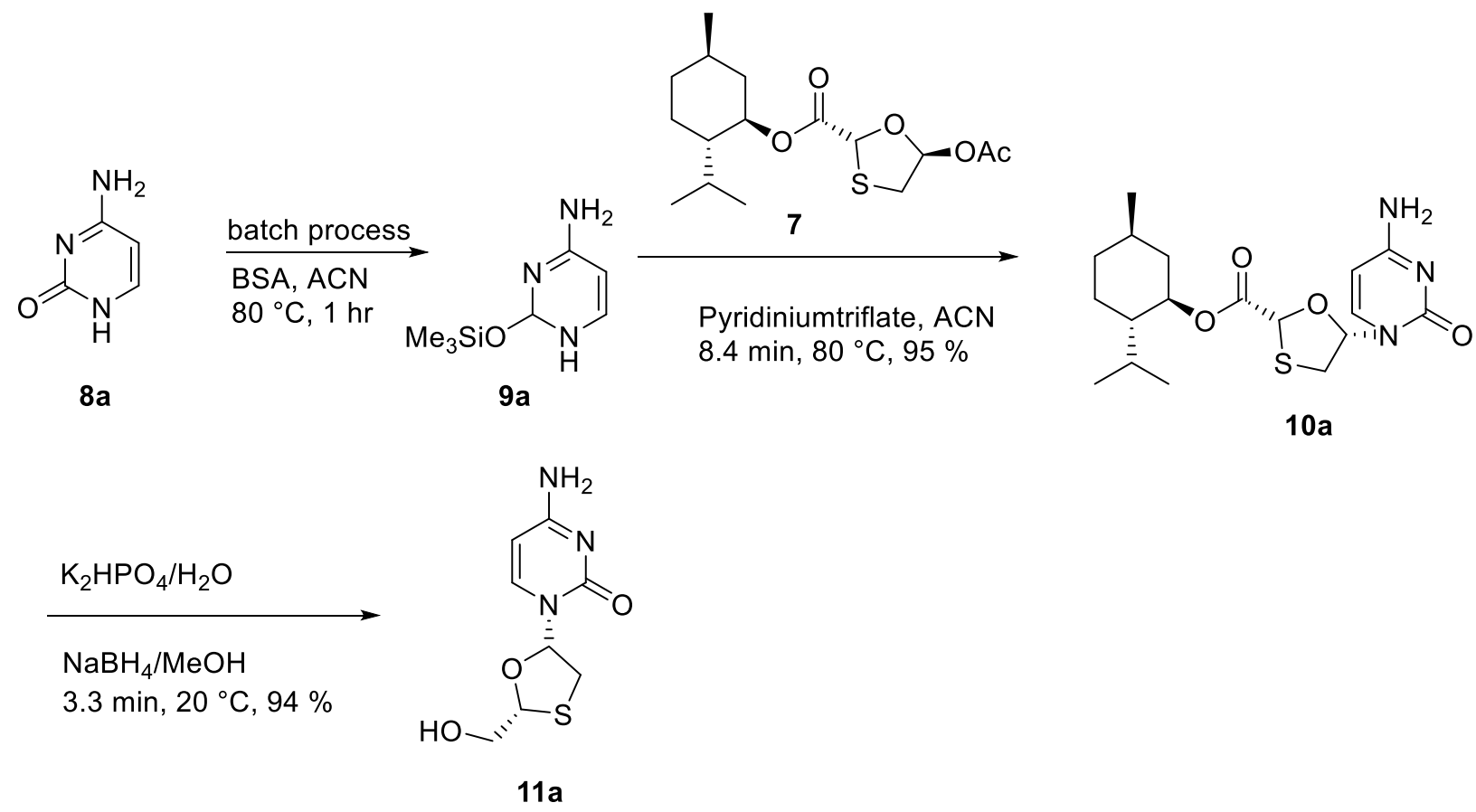

Scheme 2. Synthesis of Lamivudine.

The final step involved the removal of the menthol by the action of $\mathrm{K}_{2} \mathrm{HPO}_{4}$ in water in a $0.2 \mathrm{ml}$ reactor at ambient temperature (Figure 2). This was followed by the introduction of $\mathrm{NaBH}_{4}$ in basic water as a reducing agent to the reaction mixture stream in a $1.3 \mathrm{ml}$ reactor $(0.2 \mathrm{ml}$ static mixer $+1.1 \mathrm{ml}$ LTF reactor) which was allowed to react at ambient temperature over a residence time of 3.3 mins affording lamivudine (94\% isolated yield, $99.81 \%$ ee) (Figure 2 ).

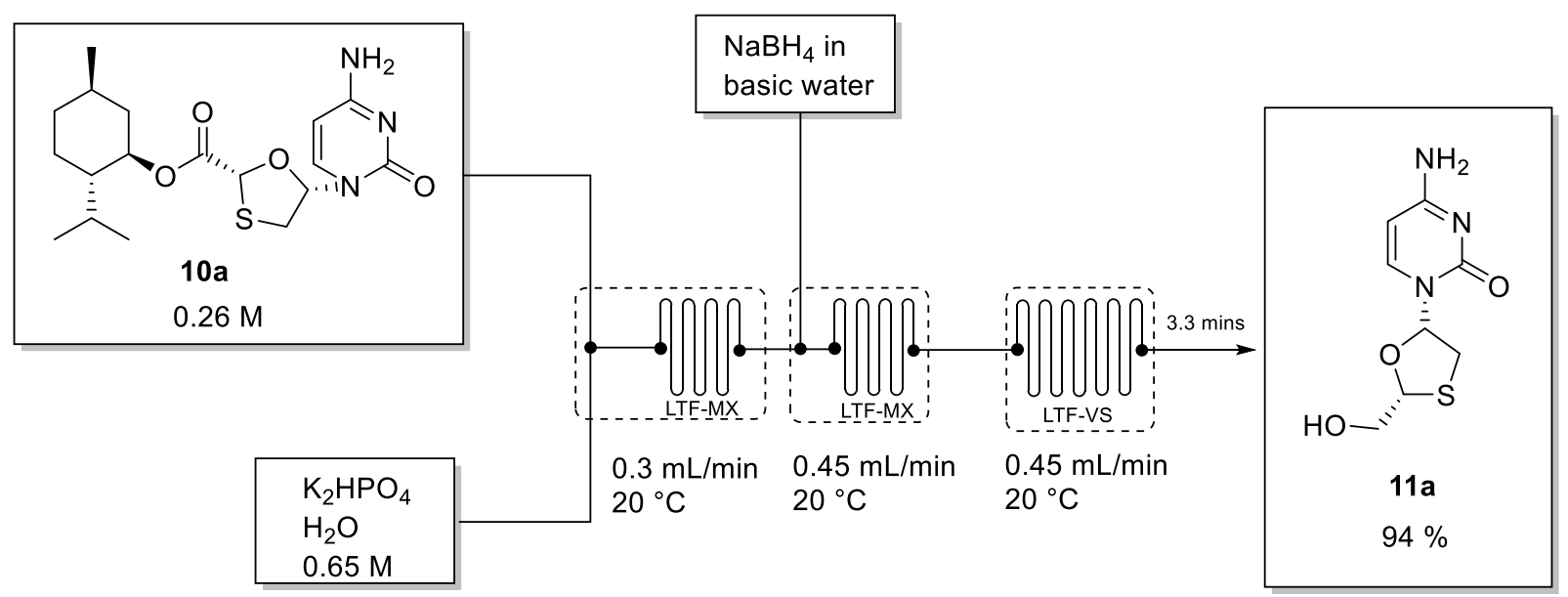

Figure 2. Reduction of nucleosides 10 a with $\mathrm{NaBH}_{4}$.

The semi-continuous flow synthesis of lamivudine 11a and emtricitabine 11b developed highlighted the advantages of using flow chemistry technology in that higher yields and selectivity's were obtained when compared to batch, with shorter reaction times and lower temperatures. 
2.1.2. Efavirenz. Chada and co-workers developed a method for the synthesis of tert-butyl-4-chloro-2-(2,2,2trifluoroacetyl)-phenyl carbamate 14 an important intermediate in the synthesis of efavirenz an essential drug in the treatment of HIV/AIDS. ${ }^{34}$ Their method involved the ortho-lithiation of $N$-Boc-4-chloroaniline 12 with $n$ BuLi in a $1.3 \mathrm{ml}$ reactor $(0.2 \mathrm{ml}$ static mixer $+1.1 \mathrm{ml}$ LTF reactor $)$ at $-45{ }^{\circ} \mathrm{C}$. The dianion eluent was subsequently trifluoro-acetylated with piperidine trifluoroacetic acid 13 in a $1.3 \mathrm{ml}$ reactor $(0.2 \mathrm{ml}$ static mixer $+1.1 \mathrm{ml}$ LTF reactor) at $-45^{\circ} \mathrm{C}$ and quenched inline via a silica packed column. The desired product 14 was obtained at a much higher yield in flow (70\%) and a residence time of 8.6 min compared to the batch process (24\%) (Figure 3). By employing a higher temperature, they were able to obtain higher yield of the desired product with less equivalents of $n$-BuLi. Additionally, their flow synthetic route did not require tetramethylethylenediamine (TMEDA), a complexing agent used to enhance the metalation reaction and increases the stability of the intermediate. The elimination of TMEDA from the flow reaction was beneficial in that it simplified the work up process.

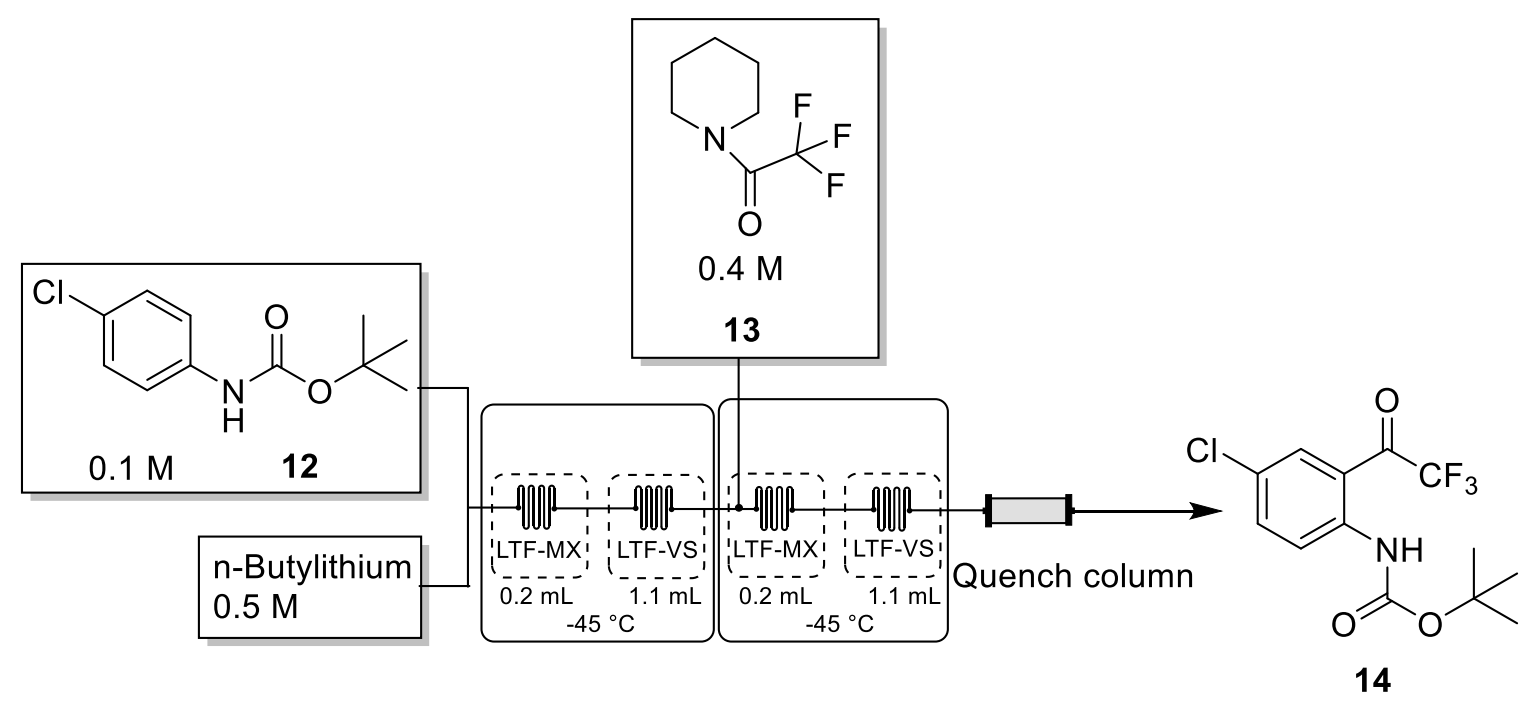

Figure 3. Flow schematic for the synthesis of tert-Butyl-4-chloro-2-(2,2,2-trifluoroacetyl)-phenyl carbamate.

2.1.3. Oseltamivir phosphate. Sagandira and Watts developed a complete flow synthesis route for the synthesis oseltamivir phosphate (Tamiflu) used in the treatment of influenza A and influenza B. ${ }^{35,36}$ The authors started by trimesylation of ethyl shikimate $\mathbf{1 6}$ derived from shikimic acid using mesyl chloride in the presence of TEA at ambient temperature in a $0.8 \mathrm{ml}$ PTFE continuous flow coil reactor. The reaction was carried out under sonication over residence time of $12 \mathrm{~s}$ affording mesyl shikimate 16 in $92 \%$ isolated yield. Subsquently, the first azidation of one of the ortho mesylate groups was performed in a $19.5 \mu \mathrm{L}$ reactor at 50 ${ }^{\circ} \mathrm{C}$ for 30s to afford the desired azide 17 in $91 \%$ yield. There was an interjection in telescoping the reactions and so the following step was the aziridination of 17 using (EtO) ${ }_{3} \mathrm{P}$ in a $19.5 \mu \mathrm{L}$ reactor at $190{ }^{\circ} \mathrm{C}$ to give aziridine 18. Due to the harzadous nature and problems associated with handling azides we investigated alternative method in which the azide was produced in situ. The multi-step process involved azidating mesyl shikmate with DPPA followed by aziridination with (EtO) ${ }_{3} \mathrm{P}$ to afford aziridine 18 in $84 \%$ yield in 25 s residence time over the two steps.

Aziridine 18 opening was performed in a $19.5 \mu \mathrm{L}$ using 3-pentanol in the presence of boron trifloride etherate at $100{ }^{\circ} \mathrm{C}$. The reaction only required $12 \mathrm{~s}$ to give an isolated yield of $95 \%$ of 3-pentyl ether 19. 
Telescoped synthesis of 3-pentyl ether 19 from azide 16 via in situ aziridine 18 formation gave $87 \%$ yield with 20 s residence time over the two steps.

The subsequent step involved the formation of the acetamide $\mathbf{2 0}$ via a tandem of reactions; first $\mathrm{H}_{2} \mathrm{SO}_{4}$ was employed to cleave the N-P bond in 3-pentyl ether 19 in a $19.5 \mu \mathrm{L}$ glass reactor at $170{ }^{\circ} \mathrm{C}$. This was immediately followed by the acetylation with $\mathrm{Ac}_{2} \mathrm{O}$ in a $19.5 \mu \mathrm{l}$ glass reactor at ambient temperature. Acetamide $\mathbf{2 0}$ was produced over a total residence time of $30 \mathrm{~s}$ with an isolated yield of $93 \%$. Sodium azide was again employed in the second azidation step of acetamide 20 in a $19.5 \mu \mathrm{L}$ glass reactor at $190{ }^{\circ} \mathrm{C}$ affording azide $\mathbf{2 1}$ (89\% isolated yield) in $45 \mathrm{sec}$. Oseltamivir 22 was obtained by the reduction of azide $\mathbf{2 1}$ using $\mathrm{NaBH}_{4}$ in the presence of catalytic $\mathrm{CoCl}_{2}$ which were allowed to react under sonication at room temperature in a 0.8 $\mathrm{mL}$ PTFE coil reactor yield $93 \%$ of the desired product in $5 \mathrm{sec}$. In the final step, Oseltamivir 22, was treated with $\mathrm{H}_{3} \mathrm{PO}_{4}$ in a $0.8 \mathrm{ml}$ PTFE continuous flow coil reactor under sonication at $50^{\circ} \mathrm{C}$ and $60 \mathrm{~s}$ residence time to afford the desired drug, oseltamivir phosphate 22 in $95 \%$ isolated yield.

This work demostrated the value and potential of flow chemistry in handling hazardous azide chemistry which was preciously shun upon. The synthetic route towards the synthesis of oseltamivir phosphate demonstrated that the drug could be synthesised in a record time, with a total residence time of 3.5 mins with an overall yield of $54 \%$ for the untelescoped process while the semi telescoped process gave a yield of $48 \%$, which dwarfs the literature reaction times of more than 30 hours.
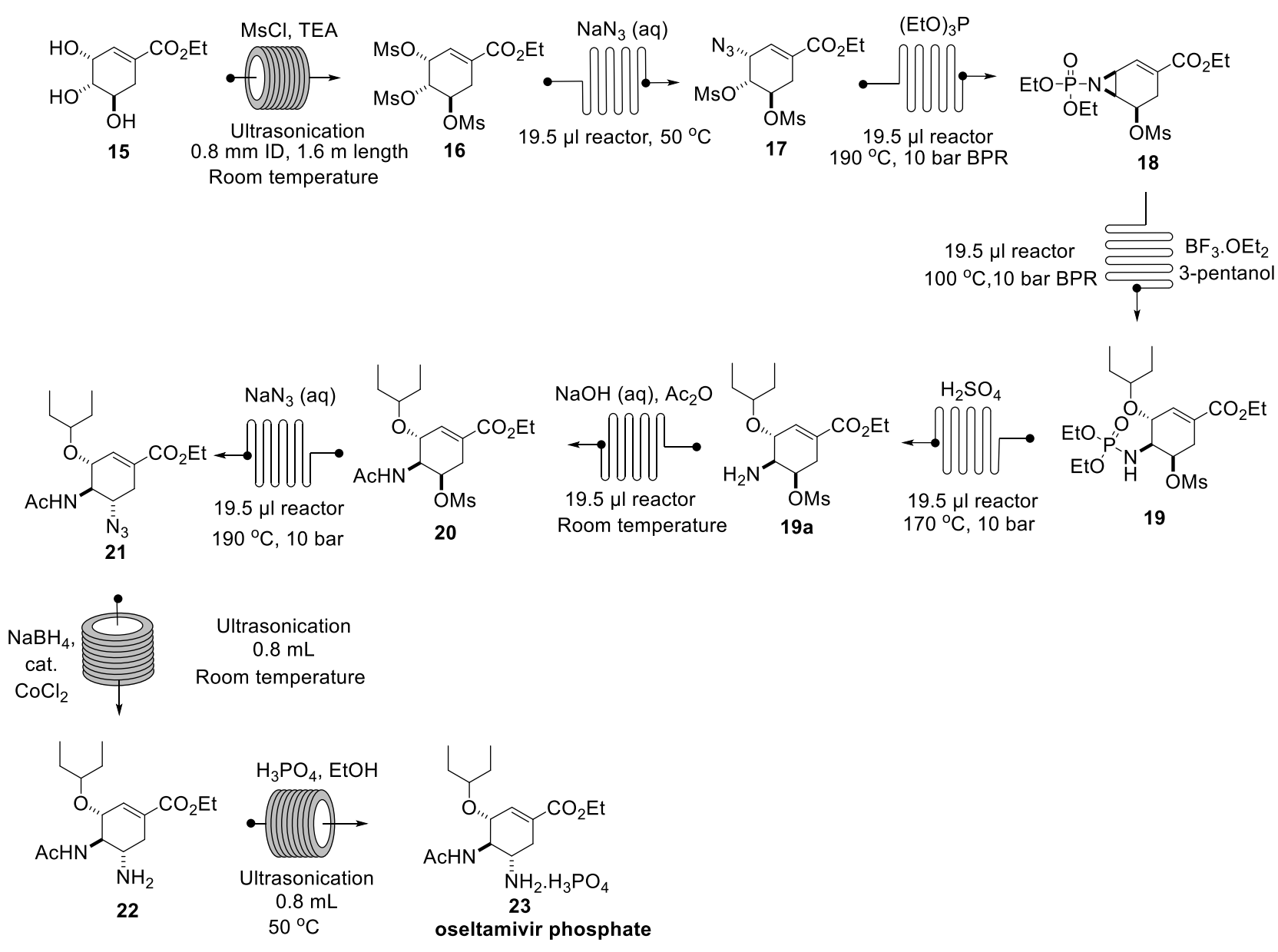

Scheme 4. Synthesis of oseltamivir phosphate. 
2.1.4. Isoniazid. Mangwiro and co-workers filed a patent on a two-step continuous flow procedure for the preparation of isoniazid 26. Isoniazid is first line drug used in the treatment of tuberculosis (TB), one of the major causes of mortality in Africa. The scourge of TB is exacerbated by the fact that it affects people with weak immune system such as people with HIV/AIDS. The first step is the hydrolysis of nitrile 4-cyanopyridine 24 in $\mathrm{MeOH}$ and $\mathrm{H}_{2} \mathrm{O}$ with aqueous $\mathrm{NaOH}$ at $95{ }^{\circ} \mathrm{C}$ in a $1.7 \mathrm{ml}$ reactor. In the second stage, the eluent stream was reacted with hydrazine hydrate 25 at $105^{\circ} \mathrm{C}$ in a $2.4 \mathrm{ml}$ reactor to afford the desired product isoniazid 26 in $96 \%$ overall conversion with 21 min total residence time over the two steps (Figure 4).

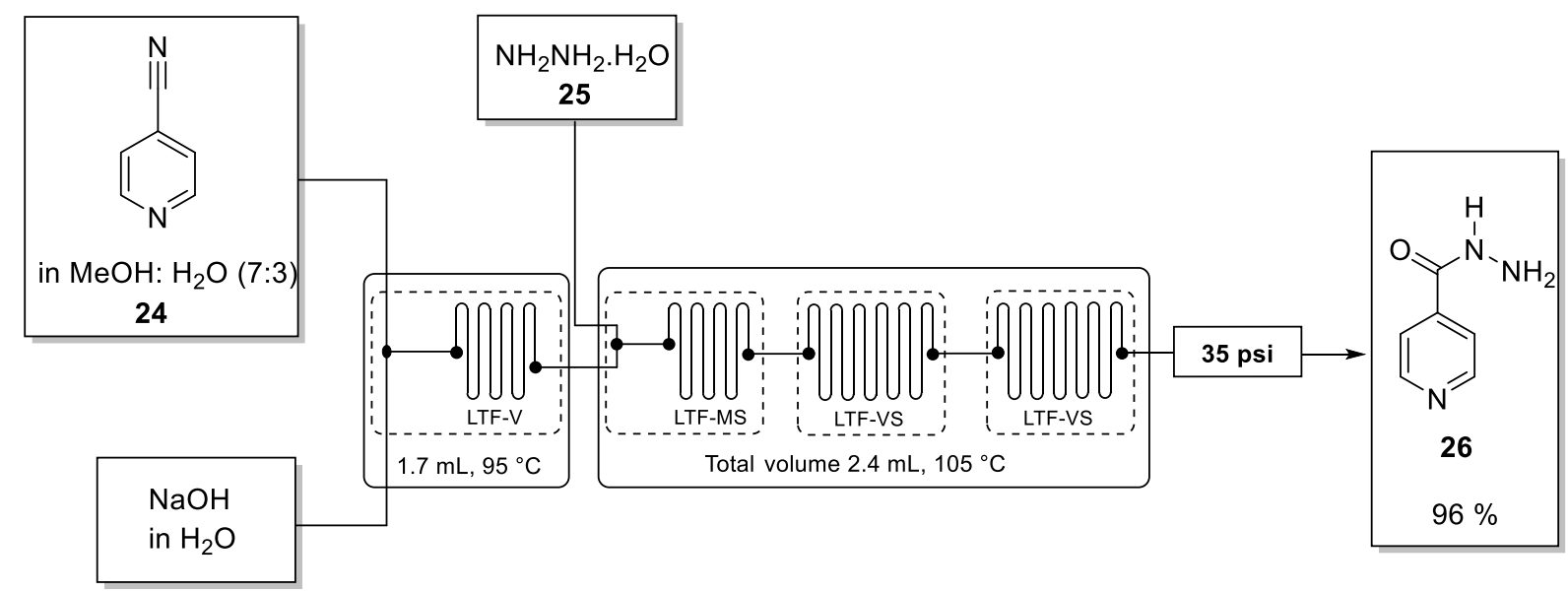

Figure 4. Synthesis of Isoniazid 26.

2.1.5. Clozapine. In 2017, the Riley group demonstrated a batch-flow hybrid synthesis of an atypical antipsychotic agent clozapine 33 used for treatment of schizophrenia. ${ }^{37}$ Their work highlighted the integration of downstream processes such as on-the-fly purification by trituration, filtration, drying and solvent swap in a four-stage continuous flow synthesis of clozapine. The first stage involved copper mediated Ullman/Goldberg coupling between anthranilic acid $\mathbf{2 7}$ and 2-bromo-4-chloronitrobenzene $\mathbf{2 8}$ in iso-propanol in the presence potassium carbonate under reflux for $8-12 \mathrm{~h}$ in batch with an integrated inline work-up and purification to afford the desired diaryl product 29 in $80 \%$ yield. In the second stage, pure stock solution of diaryl 29 was pumped through a $2 \mathrm{ml}$ mixing chip at $25{ }^{\circ} \mathrm{C}$ under novel reductive conditions (sodium dithionite/aqueous ammonia) in $92 \mathrm{~s}$ residence time. Isolated yield of $79 \%$ for product $\mathbf{3 0}$ as a standalone step after on-the-fly trituration, precipitated and vacuum dried which was subsequently re-solubilised in anhydrous THF prior to passage into the next stage. The third stage involved intramolecular amide coupling. Product $\mathbf{3 0}$ was pumped through a polymer supported EDC and afforded product 31 in 76\% isolated yield as a standalone step with 3.5 $\mathrm{h}$ residence time. Without any purification, product $\mathbf{3 1}$ was pumped into a solvent swapper to enable the use of toluene in last stage which needs to be heated in excess of $100{ }^{\circ} \mathrm{C}$ in batch. The final step involved a $\mathrm{TiCl}_{4}$ mediated chlorination of $\mathbf{3 1}$ followed by immediate treatment with $N$-methyl piperazine $\mathbf{3 2}$ to displace the chloride and heated at $110{ }^{\circ} \mathrm{C}$ for $24 \mathrm{~h}$. Clozapine 33 was afforded in $72 \%$ over two stages ( 3 and 4).

The telescoped hybrid process on $1 \mathrm{~g}$ scale afforded clozapine 33 in $45.5 \%$ in overall yield and $44 \mathrm{~h}$ residence time which better that a purely batch process $(27 \%, 132 \mathrm{~h}$ reaction time). This remarkable improvement can be attributed to the use of flow chemistry technology in the second and third stage of the process further reaffirming the power of the technology. 


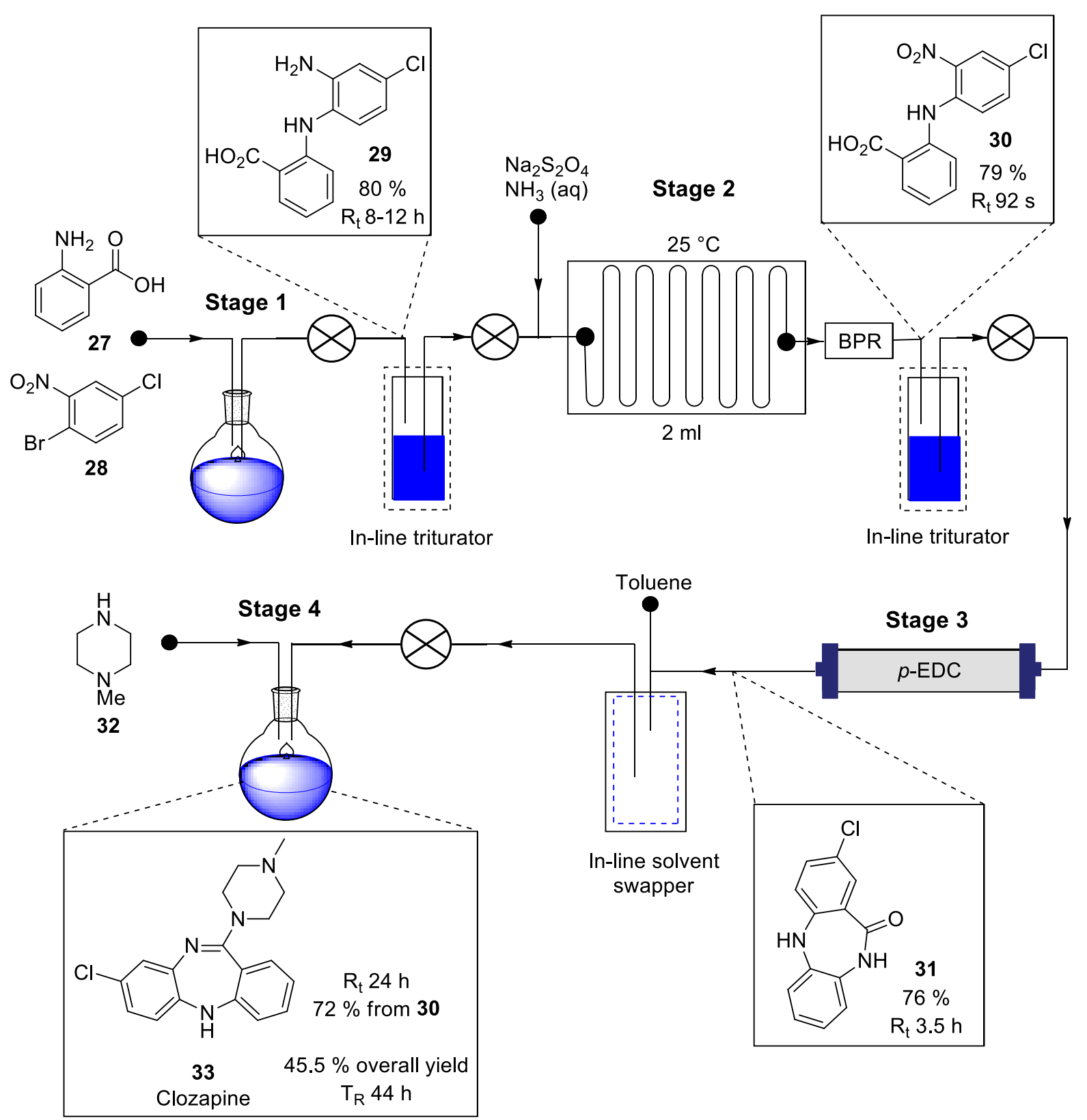

Scheme 5. Clozapine synthetic route.

\section{Conclusions}

Flow chemistry is an emerging technology which has impacted the pharmaceutical industry due to its numerous benefits such as energy, cost savings, safety and versatility. This review demonstrated that drugs of importance can be made cost effectively from basic starting materials with the ability to develop multi-step continuous flow systems in Africa. The technology can be adopted for both research and industry with the ability to rapidly screen conditions for synthesis of drugs for production which can be scaled up for manufacturing with ease. Undoubtably, Africa can build on the ongoing capacity building of continuous flow manufacture of APIs to establish state-of-the-art manufacturing infrastructure in the near future that will answer the current drug availability concerns. The adoption of continuous flow manufacturing in combination 
with other information technologies such as automation and artificial intelligence offers a strong business case to increase accessibility of drugs in Africa thus simultaneously improving the health and economy of the continent.

\section{Acknowledgements}

We thank the National Research Foundation and Nelson Mandela University for financial support.

\section{References}

1. Dixon, S.; McDonald, S.; Roberts, J. Br. Med. J. 2002, 324, 232-234.

2. Adedeji, W. A., Ann. Ibadan Postgrad. Med., 2016, 14, 56-57.

3. Mabuza, H. CDC Global Health - South Africa, 2011, 1-9.

4. Ngozwana, S.; West, A.; Olajide A.; Byaruhanga, J. Pharmaceutical manufacturing Plan for africa Business plan, Addis Ababa, 2012, 1-102.

5. Riley, D. L.; Strydom, I.; Chikwamba, R.; Panayides, J. L. React. Chem. Eng., 2019, 4, 457-489. https://doi.org/10.1039/c7re00146k

6. Tadesse B. T.; Ashley, E. A.; Ongarello, S.; Havumaki, J.; Wijegoonewardena, M.; González, I. J.; Dittrich, S. BMC Infect. Dis., 2017, 17, 1-17.

https://doi.org/10.1186/s12879-017-2713-1

7. Oliphant, C. M.; Green, G. M. Am. Fam. Physician, 2011, 65, 455-464.

https://doi.org/10.3109/13880209.2010.497815

8. O'Neill, J. Tackling drug-resistant infections globally: Final report and recommendations, 2016, 136, 1-84.

9. Kaplan W.; Laing, R. Heal. Nutr. Popul., 2005, 1-54.

10. Wilson, K.; Cohen-köhler, J.; Whiteside, A. Eurohealth (Lond). 2008, 14, 29-32. http://dx.doi.org/10.1371/journal.pmed.0050143

11. U.S. Food and Drug Admnistration, Development \& Approval Process (Drugs) - Orange Book Preface, 2015, 1-15.

12. Boulle, A.; Bock, P. Osler, M.; Cohen, K.; Channing, L.; Hilderbrand K.; Mothibi, E.; WHO Antiretroviral therapy and early mortality in South Africa, 2014, 1-12.

13. Beukes, S. Aspen Holdings, ARV's, 2019, 1-5.

14. Pinheiro, S.; Brüning, K.; Macedo M. F.; Siani, A. C. Antivir. Ther., 2014, 19, 49-55. http://dx.doi. org/10.3851/IMP2900

15. Smart, T. National Strategic Plan Report, 2015, 1-8.

16. de Souza R. O. M. A.; Watts P. J. Flow Chem. 2017, 7, 146-150.

http://dx.doi.org/10.1556/1846.2017.00019

17. Wiles C.; Watts, P. Green Chem. 2014, 16, 55-62.

http://dx.doi.org/10.1039/c3gc41797b

18. McWilliams, J. C.; Allian, A. D.; Opalka, S. M.; May, S. A.; Journet M.; Braden, T. M. Org. Process Res. Dev., 2018, 22, 1143-1166.

http://dx.doi.org/10.1039/c3gc41797b

19. Jensen, K. F. AIChE J. 2017, 63, 858-869. 
http://dx.doi.org/DOI:10.1002/aic.15642

20. Baxendale, I. R. J. Chem. Technol. Biotechnol., 2013, 88, 519-552.

http://dx.doi.org/10.2174/138620707783220374

21. Wegner, J.; Ceylan, S.; Kirschning, A. Adv. Synth. Catal., 2012, 354, 17-57.

http://dx.doi.org/10.1002/adsc.201100584

22. McMullen, J. P.; Marton, C. H.; Sherry, B. D.; Spencer, G.; Kukura J.; Eyke, N. S. Org. Process Res. Dev., 2018, 22, 1208-1213.

http://dx.doi.org/10.1021/acs.oprd.8b00192

23. Cole, K. P.; Groh, J. M.; C. Johnson, M. D.; Burcham, C. L.; Campbell, B. M.; Diseroad, W. D.; Heller, M. R.; Howell, J. R.; Kallman, N. J.; Koenig, T. M.; May, S. A.; Miller, R. D.; Mitchell, D.; Myers, D. P.; Myers, S. S.; Phillips, J. L.; Polster, C. S.; White, T. D.; Cashman, J.; Hurley, D.; Moylan, R.; Sheehan, P.; Spencer, R. D.; Desmond, K.; Desmond, P.; Gowran, O.; Science, 2017, 356, 1144-1151.

http://dx.doi.org/10.1126/science.aan0745

24. Frederick, M. O.; Calvin, J. R.; Cope, R. F.; Letourneau, M. E.; Lorenz, K. T.; Johnson, M. D.; Maloney, T. D.; Pu, Y. J.; Miller, R. D.; Cziesla, L. E. Org. Process Res. Dev., 2015, 19, 1411-1417.

http://dx.doi.org/10.1021/acs.oprd.5b00240

25. Porta, R.; Benaglia M.; Puglisi, A. Org. Process Res. Dev., 2016, 20, 2-25.

http://dx.doi.org/10.1021/acs.oprd.5b00325

26. de Souza, J. M.; Galaverna, R.; de Souza, A. A. N.; Brocksom, T. J.; Pastre, J. C.; de Souza R. O. M. A.; de Oliveira, K. T.; An. Acad. Bras. Cienc., 2018, 90, 1131-1174.

http://dx.doi.org/10.1590/0001-3765201820170778

27. Hughes, D. L. Org. Process Res. Dev., 2018, 22, 13-20.

http://dx.doi.org/10.1021/acs.oprd.7b00363

28. Tsubogo, T.; Oyamada H.; Kobayashi, S. Nature, 2015, 520, 329-332.

http://dx.doi.org/10.1038/nature14343

29. Yu, E.; Mangunuru, H. P. R.;Telang, N. S.; Kong, C. J.; Verghese, J.; Gilliland, S. E.; Ahmad, S.; Dominey R. N.; Gupton, B. F. Beilstein J. Org. Chem., 2018, 14, 583-592.

http://dx.doi.org/10.3762/bjoc.14.45

30. Kulkarni, A. A.; Zeyer, K .; Jacobs T.; Kienle, A. Ind. Eng. Chem. Res, 2007, 46, 5271-5277. http://dx.doi.org/10.1039/c8re00025e

31. Ziegler, R. E.; Desai, B. K.; Jee, J. A.; Gupton, B. F.; Roper T. D.; Jamison, T. F. Angew. Chemie - Int. Ed., 2018, 57, 7181-7185.

http://dx.doi.org/10.1002/anie.201802256

32. Mandala, D.; Watts, P. ChemistrySelect, 2017, 2, 1102-1105. http://dx.doi.org/10.1002/slct.201700052

33. Caso, M. F.; Dalonzo, D.; Derrico, S.; Palumbo G.; A. Guaragna, Org. Lett., 2015, 17, 2626-2629. http://dx.doi.org/10.1021/acs.orglett.5b00982

34. Chada, S.; Mandala D.and P. Watts, J. Flow Chem., 2017, 7, 37-40. http://dx.doi.org/10.1039/c7ob00480j

35. Sagandira, C. R.; Watts, P. Synlett. 2020, in press.

36. Sagandira, C. R., Watts, P. Beilstein J. Org. Chem. 2019, 15, 2577-2589.

http://dx.doi.org/10.3762/bjoc.15.251

37. Neyt, N. C.; Riley, D. L. React. Chem. Eng. 2018, 3, 17-24. http://dx.doi.org/10.1021/acs.orglett.5b00982 


\section{Authors' Biographies}

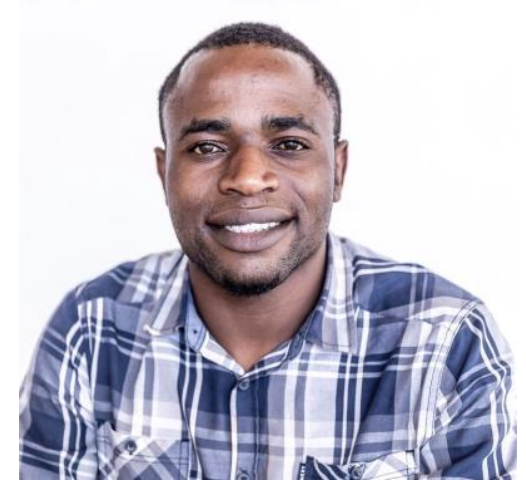

Cloudius R. Sagandira graduated with a BSc in Biochemistry and Chemistry from the Nelson Mandela University in 2014 where he went on to receive his Honours degree in Formulation Science (Cum Laude) in 2015. In the same year, he joined Professor Paul Watts' group as a Master of Science candidate at the same University where he worked on potentially explosive azide chemistry in continuous flow systems and graduated in 2017 with distinction. Working in the same research group, he received his chemistry PhD degree in 2019 where he developed a continuous flow synthetic procedure for oseltamivir phosphate an antiinfluenza drug. Currently, he is a postdoctoral fellow in the same research group working on the synthesis of numerous drugs in flow.

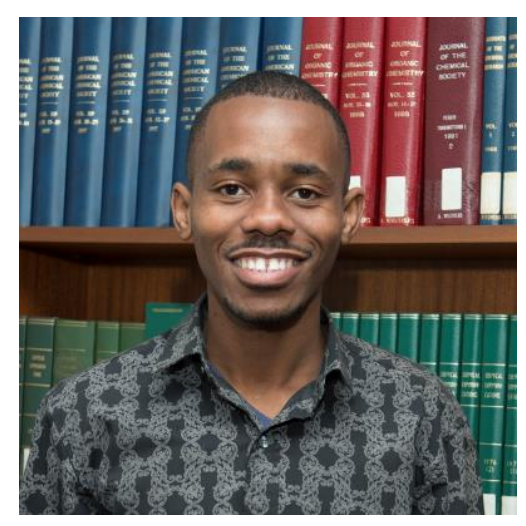

McQuillan Moyo graduated with a BSc in Biochemistry and Chemistry from the Nelson Mandela University in 2014 where he also received his Honours degree in Formulation Science in 2015. In the same year, he joined Professor Paul Watts' group at Nelson Mandela University as a Master of Science candidate, with the focus on synthesis of a key intermediate in the synthesis of lamivudine an important ARV drug using continuous flow technology. Currently he is working on the continuous flow synthesis of Gatifloxacin an antibiotic, with the goal of telescoping the process. 


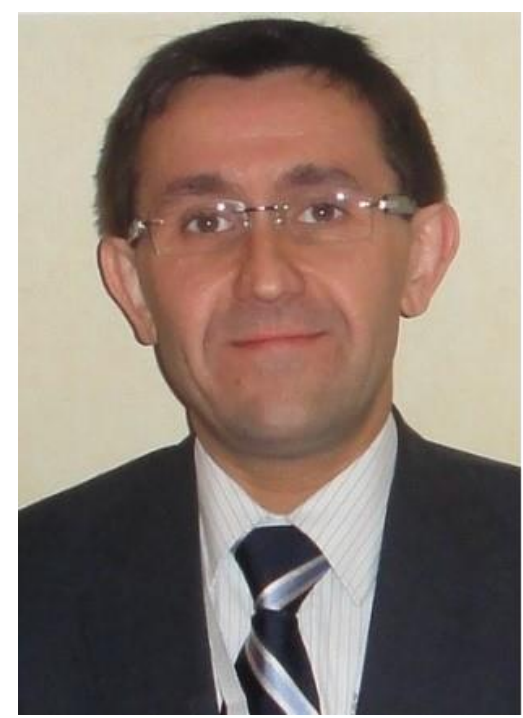

Paul Watts started his career as a lecturer at the University of Hull (UK) in 2002, being promoted to full professor in 2011. At the University of Hull he led the micro reactor and flow technology group. In February 2013, he moved to Nelson Mandela University to hold the distinguished position of 'SARChI Research Chair in Microfluidic Bio/Chemical Processing'. He has published over 120 highly cited papers. He strongly believes that scientists should conduct research that impacts society; the biggest project underway involves the local production of key drugs as the morbidity and mortality from major diseases are much more devastating in Africa than in other regions of the world. The vision is that new technology will be used within South Africa to manufacture generic drugs; this could create jobs and a new manufacturing industry within the country. 